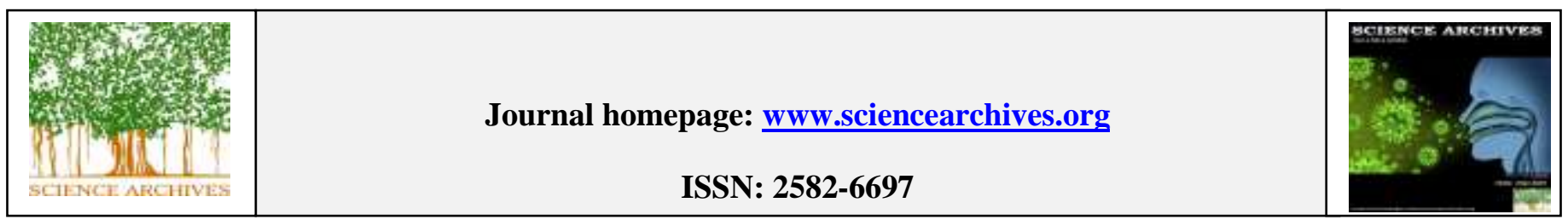

Review Article

http://dx.doi.org/10.47587/SA.2020.1202

\title{
Humic substances as an environmental-friendly organic wastes potentially help as natural anti-virus to inhibit COVID-19
}

\author{
Mohamed Hafez ${ }^{1,4 \triangleright<}$, Alexander I. Popov ${ }^{1}$, Valery N. Zelenkov ${ }^{2}$, Tamara V. Teplyakova ${ }^{3}$, and \\ Mohamed Rashad ${ }^{4}$ \\ ${ }^{I}$ Department of Soil Science and Soil Ecology, Institute of Earth Sciences, Saint Petersburg State University, Embankment, \\ 7/9, Saint Petersburg, 199034, Russia \\ ${ }^{2}$ All -Russian Research Institute of Vegetable Production 140153, Moscow, Russia \\ ${ }^{3}$ Laboratory of the State Scientific Center of Virology and Biotechnology "Vector" 30659, Novosibirsk, Russia \\ ${ }^{4}$ Land and Water Technologies Department, Arid Lands Cultivation Research Institute, City of Scientific Research and \\ Technological Applications, New Borg El-Arab, 21934, Alexandria, Egypt. \\ Corresponding author $\bowtie<$ Mohamed Hafez. E-mail: mhafez290@yahoo.com \\ Received: Aug 21, 2020 / Accepted: Sept 7, 2020/ Published: Sept 29, 2020
}

\begin{abstract}
The aim of this review was trying to access information to help the world in getting rid of a nightmare COVID-19, by evaluating the anti-virus activity of humic substances as natural anti-virus to inhibit COVID-19. In this scientific review, which devoted to biomedical aspects of various origin humic substances and other organic wastes influences on living organisms, is presented. It is shown that kinds of biological activity of humic substances (HS) are an integral indicator of properties of these substances. Data on humic substances and melanin of anti-viral, anti-carcinogen, and anti-virus diseases such as (COVID-19) activity is given too by immune-modulation. Humic substances, or humates, are the end points of organic (carbon-containing) degradation. They're essentially what are left over from microbial decomposition of organisms and dead plant matter; however, they remain highly concentrated in minerals, amino acids, and fatty acids. Studies have shown that humic substances are effective against both naked and enveloped DNA viruses, including Coxsackie A9, influenza A and B, and herpes simplex type 1 and 2 viruses. In conclusion, humic substances effected on reduce oxidative stress and even induce apoptosis in hepatic cancer lines. humic substances are shown to also influence the micro-biome and possibly improve gut function. This will help make conclusive statements regarding humic substances function and its influence on immune-related diseases. The mechanism whereby humic substances inhibit the cytopathicity of a number of viruses has been studied in some depth. It is thought that the materials prevent viral replicating by sorbing onto the viral envelope protein and thereby blocking the sorption of viral particles to cell surfaces.
\end{abstract}

Keywords: Environmental- friendly, humic substances, biological activity and immune-modulation.

\section{Introduction}

Recently, the novel coronavirus COVID-19 was discovered on the late of 2019 in Wuhan city, China. COVID-19 was suddenly appeared, leading not only the health authorities, but also the scientific community to swift actions toward it. With more than 27,070,133 confirmed cases and at least 882,937 deaths across the globe, many countries and regions have imposed lockdowns in their territories to stem the spread of the corona virus. The World Health Organization (WHO), however, says it is not enough. Government and health measures against the novel corona virus, officially called the severe acute respiratory syndrome corona virus 2 (SARS-CoV2), must extend beyond large-scale lockdowns, a WHO emergency-preparedness expert said. Diseases associated with chronic inflammation such as diabetes, cardiovascular disease, and colitis have been increasing. More than 500 million of dollars have been poured into the development of drugs to treat 
these diseases with little success (WHO, 2020). Thus, it is time to explore new avenues in treating and preventing chronic inflammatory diseases. Natural health products (NHPs) may provide a promising route in this quest for alternatives. First, they require little to no development, and second, they are often accompanied by a history rich in traditional medicine. Humic substances (HS) is a publicly available NHP that combines those two facts and may provide promising outcomes for chronic inflammatory diseases.

\section{Humic substances overview}

Humic substances fall under three categories: humic acid, fulvic acid, and humin. Humic and fulvic acids are alkalisoluble residues whereas humin is an insoluble residue shown (Figure 1). Due to their smaller particle size over humin, humic and fulvic acids are what you'll find being used for their health benefits. Humic acid, fulvic and humine, extracellular decomposition products, and therefore differs in biomass, are the three core fractions of the humic substances formed through the amalgamation of biochemical and geochemical reactions. If the strong-based extract is acidified humic acid which coagulates while fulvic acid is soluble. A general alkaline extraction approach is applied to the recovery of humic and fulvic acids from soils and sediments. In the case of insulation, XAD-4 resin is favorably secured under some $\mathrm{pH}$ conditions by the hydrophilic properties of fulvic acid. The molecular weight and the attached side groups are variable in all of these fractions (Ishiwatari 1992; Saito \& Seckler 2014).
These polymers are very resistant to further microbial degradation and to a wide variety of organic combinations. In terrestrial and freshwater humic substances, recognizable levels of chemical moites derived from the lignin are usually observed, while in lignin mode marine humic substances are inadequate. Estuarine sieve differs in isotopic composition from marine and terrestrial humic substances. About 80 million years, correct geological conditions and effective mixing of organic compounds make humic substrates (Saito \& Seckler 2014).

\section{Humic substances as an Antiviral}

The inquiry on the antiviral effect of humic substances is initiated by successful battle against foot-and - mouth diseases using peat dust (Ghosal et al., 1988). Preliminary in-vitro experiments with Coxsackie A9, Influenza A and Herpes simplex type 1 (HSV-1) virus have already been demonstrated against both naked and embedded DNA viruses. Humic acid selectively inhibited certain human viruses type $1(\mathrm{HIV}-1)$ and type 2(HIV-2), cytomegalovirus (CMV), and vaccine viruses (Klocking \& Sprossig 1972; Schols et al., 1991). Humic acid has a selective inhibition effect. Results from animal experiments have confirmed that humic acid polymer affects the early stage of herpesvirus replication. The strong inhibition of HIV-1 was found to be humic-acid synthesized from hydroquinones (Schols et al., 1991). The effects of KOP, Sodium humate, and Ammonium humate on antiviral activity showed (Fig. 1). (a)

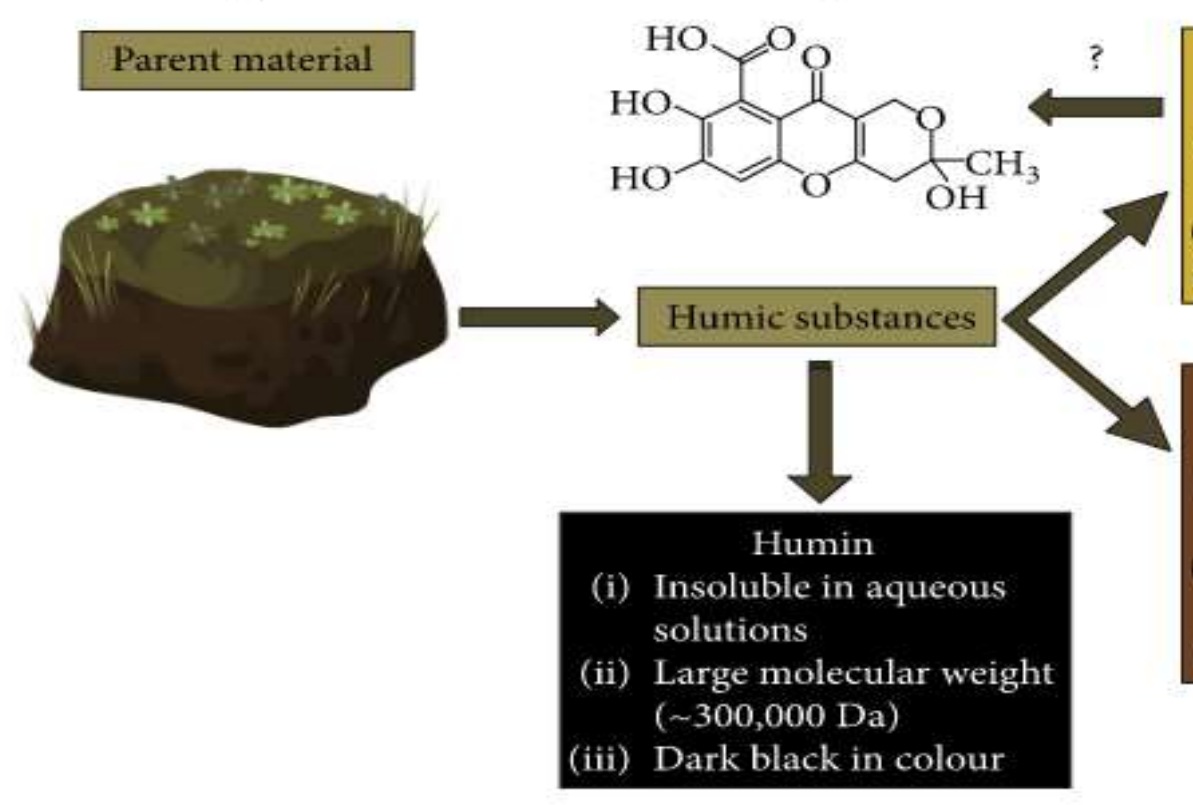

(b) 


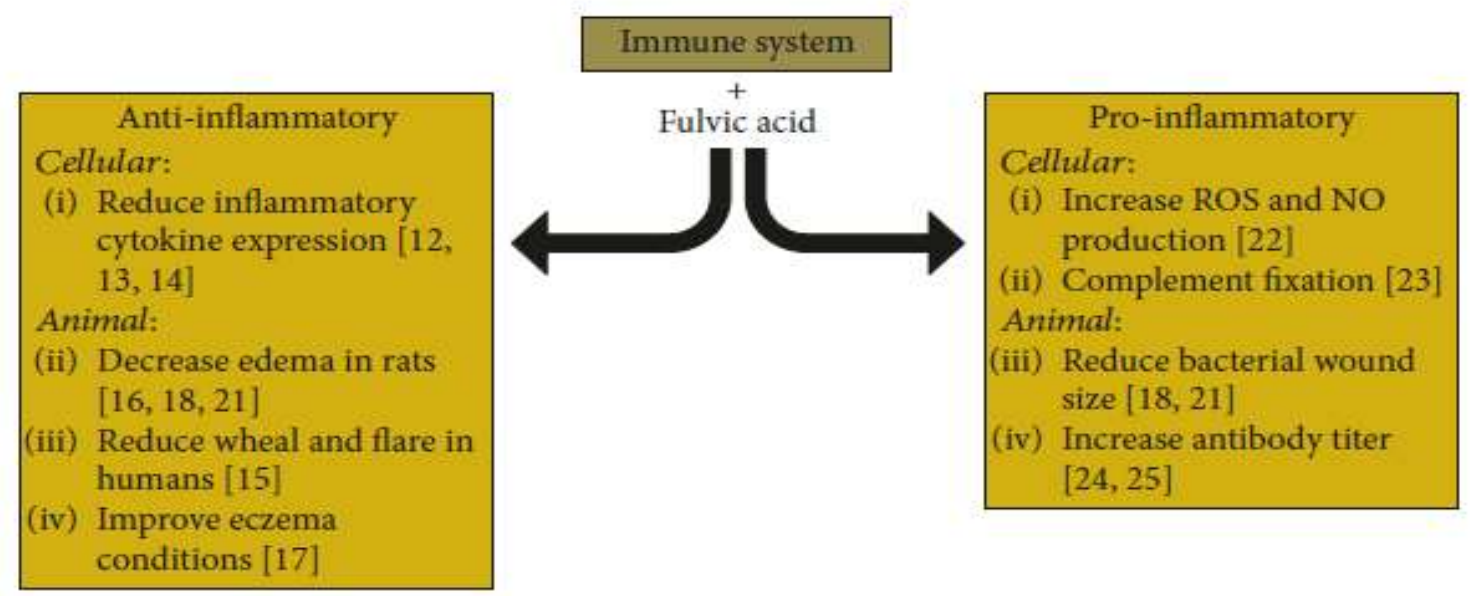

\section{Fig . 3 Known literature for the effects of fulvic acid on the immune system. Fulvic acid is shown to induce as well as reduce inflammation (John Winkler and Sanjoy Ghosh, 2018)}

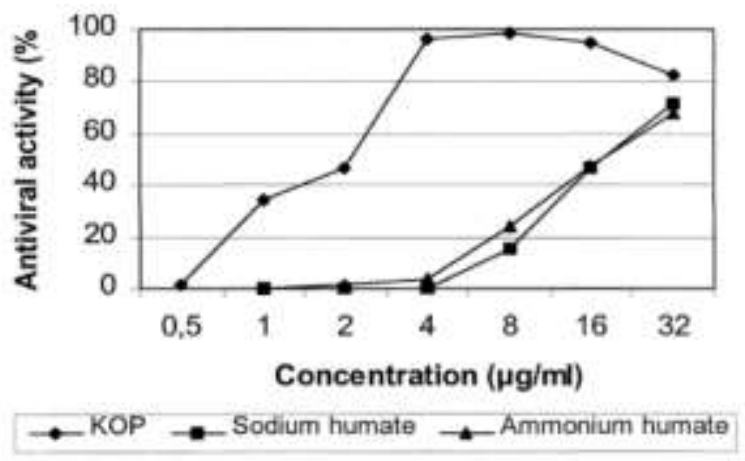

Fig. 1 Effect of KOP, Sodium humate, and Ammonium humate on antiviral activity (\%)

\section{Role of Humic Substance (HS) to inhibit Covid-19}

One of the important properties of HS, including melanin compounds, is their biological activity. According to the point view (Ovchinnikova, et al. 1991), HS by the nature of the effect on COVID-19, fungi and other organisms, it is possible attributed to non-specific growth regulators. How considers, the nature of the biological activity of HS, affecting the growth and development of animals, is also a combination various mechanism (Ilycheva et al., 2014).The formation of humic acids in nature is the interaction of organic and inorganic processes. It is hypothesized that these processes laid the foundation for the formation of organic life on Earth. It is natural to assume that in the process of evolution of the higher life form, it was also actively involved, which was proved by numerous clinical trials. The adapto-genic and bio stimulating effect of these compounds leads to the fact that such considered incurable diseases as oncology or int-COVID-19 infection are retreating (Ilycheva et al., 2014). Humic acid introduced into the composition of biologically active additives, the human benefit of which has been confirmed by many cases of the cure for serious diseases helps to reverse these seemingly irreversible processes.

The biological activity of HS may be due to (Popov 2004):

- The presence in these compounds of diverse functional groups;

- Colloidal properties;

- Component composition.

The presence in the HS of a variety of functional groups determines, firstly, the participation of these compounds in chemical oxidation-reduction reactions, and, secondly, the reactivity in generally, including ion exchange and the formation of chelate compounds. Being colloids, HS show surface active and electro-surface properties. These properties determine hydrophilic hydrophobic and electrostatic interactions. humic compounds (Ishiwatari 1992; Saito \& Seckler 2014).

\section{Immunomodulation by Humic acid (HA) and Fulvic acid (FA)}

The most adequately researched claim of $\mathrm{HA}$ and FA is its ability to modulate the immune system. However, the outcomes of such studies remain controversial. HA and FA can be both proinflammatory and anti-inflammatory in animal systems. The available literature regarding the effects of HA and FA on the immune system is summarized shown in (Figure 3), anti-inflammatory effects of HA and FA. Asthma, allergies, and eczema, along with many other disorders, can be associated with overactive immune cells (Belousov et al., 2014). In these cases, anti-inflammatory drugs are critical for reducing symptoms for COVID-19. Several studies indicate that HA and FA can act as an anti-inflammatory by reducing the release of proinflammatory mediators from cells. (Popov 
2004) Show that HA and FA at $200 \mu \mathrm{g} / \mathrm{mL}$ can reduce tumour necrosis factor alpha (TNF- $\alpha$ ) expression after exposure to the endotoxin Lipopolysaccharide (LPS) in differentiated human monocytes (U937) (Kornilayeva et al., 2010). HA and Fv.A also is shown to reduce cyclooxygenase 2 (COX2) and prostaglandin E2 (PGE2) secretion after homocysteine stimulation in primary human monocytes (Lishtvan et al., 2004).

Humic substances, beinghetero-polymers of aryl glycoprotein nature can serve as a source of structural fragments organic macromolecules during biosynthesis in living organisms (Popov, 2004). Consider the literature in the relationship functional and structural features of the organization of HS with manifestations of their biological activity, changing the picture of various parameters vital functions of the body systems and its chemical, physico-chemical, energy and other characteristics (Klocking \& Sprossig 1972; Schols et al., 1991). The In this study, we are aim on based on previous works to: Humic compounds can be used as micro-biocides, prophylactic agents against the spread of COVID-19; the cytotoxic and antiviral properties of humic acids and fulvic acids isolated from humic substances. Humates bolster the immune system. Dr. Daryl See, MD, formerly an Immunologist of UCI Medical School, suggests that the mechanism is related to the humates ability to complex (assemble) sugars within the body. The abundance of these complexed sugars allows the body to manufacture glycoproteins that attach to the killer and $\mathrm{T}$ cell acting as a modulator or communication link between the cells. This regulates the immune system cells and prevents either the $\mathrm{T}$ or Killer cells from becoming out of balance. Excessive killer cells can attack bone and joints causing arthritis. Conversely, excessive $\mathrm{T}$ cells can cause auto-immune diseases.

\section{Participation of Humic Substances in Redox Reactions of Living Organisms}

Figure (4) showed humic substances are donors and acceptors of electrons and protons, and therefore humic acids can participate in various redox reactions, including reversible ones (Popov 2004). So, on rat mitochondria liver was shown that HS after a short exposure with the object was partially interrupted oxidative phosphorylation, while incubation of mitochondria with HS for a longer period ended with a positive impact on oxidative phosphorylation (Visser 1987). In experiments in vitro has been shown (Belousov et al., 2014) that HS are able to directly oxidize and reduce Ferriccytochrome C. All HS fractions had antioxidant activity, which increased in the series: fulvic acids - humic acids - hematomelanic acids and depended on the structural features of the compounds that determine the factor of which is the nature of the pairing. In particularly high antioxidant activity (in vitro) of hemato-melanic acids is due to conjugation of the quinoidphenol type with the inclusion of ester fragments (Zhdanova 2011).

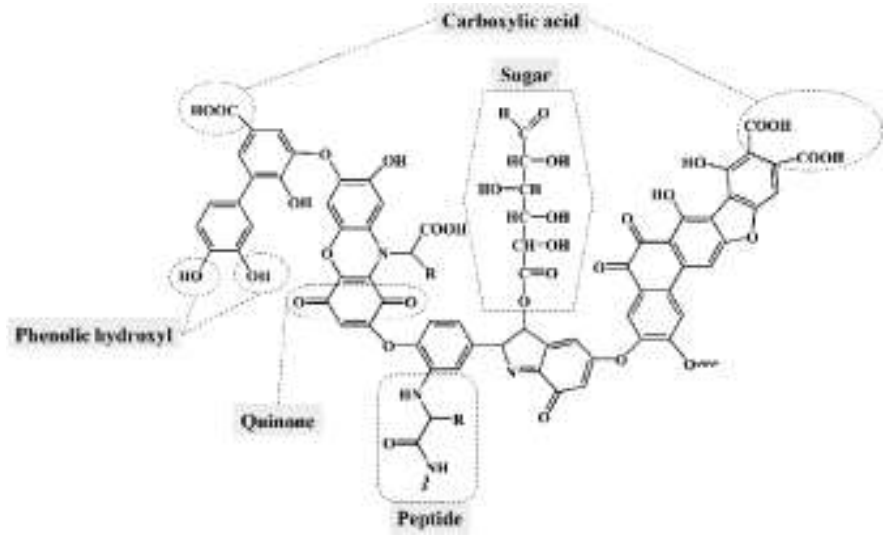

Fig, 4. Chemical structure of Humic Acid

\section{Bio-reactive Ability Humic Substances}

The bio-reactivity of HS is manifested in effects on osmotic pressure, in enzyme-substrate interactions, in the detoxification of xenobiotic substances and compounds, as well as in some other processes (Popov 2004). At the same time, HS and chaga can increase the intake of in living organisms, for example, in mussels (Mytilustrossulus Gould), compounds of toxic metals, in particular cadmium (Zhdanova 2011). The influence of HS has, more selective and variable, and also depends on the concentration of humic acids and the acidity of the medium (Clapp \& Chen 2001). The ability of HA and chaga to form strong complexes with metal cations can interfere with the osmotic regulation of aquatic invertebrates, in particular caddis flies. Absorption of chaga and HS properties higher than charcoal or clay. Humic substances are able to take an active part in enzyme-substrate interactions (Popov 2004; Buzlama \& Chernov 2010), while it was identified as an increase in activity enzyme systems and their inhibition. The inconsistency of information about the action of humic acids enzymatic activity may be explained as different concentrations, values of the hydrogen index $(\mathrm{pH})$ and ionic strength of the HS and chaga solutions, used in experiments and properties these natural specific polymers (e.g., molecular weight, biochemical composition, the amount of free radicals, etc.), as well as synergistic or antagonistic phenomena. According to (Kitapova \& Ziganshin 2015) HS macro-radicals can interrupt the chain process bio-catalysis by recombining with intermediate free radicals. As a result of this interaction, inactivation of enzymes occurs. Besides of this, HS and chaga can form compounds with proteins - humic-protein complexes, the latter under the influence of various coagulating factors are able to inhibitionCOVID-19 (Koginov 1962). In addition, humic acids with respect to peroxidase are able to act simultaneously in three qualities - as a product of peroxidase reactions, an immobilizing agent and a nonspecific substrate (Khaziev \& Gulko 1990). 


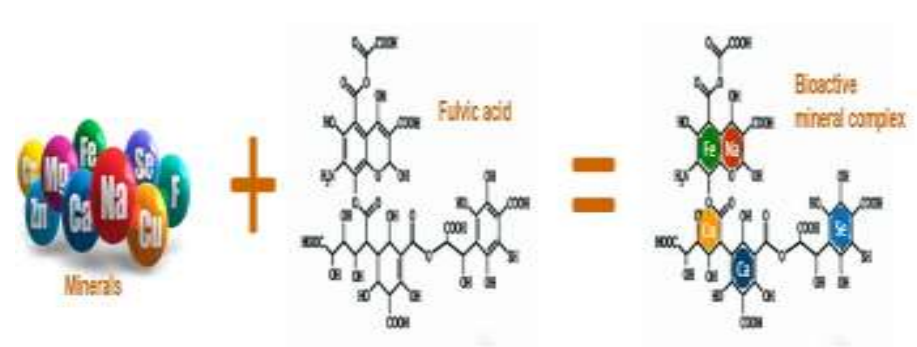

Fig. 5. Chemical composition of FA chelating for minerals

The effects of hepatitis HS are manifested, affecting the functions of cell membranes. (Figure 5) show increase in ionic strength and the acidity of the mineral solution contributed to the permeability of organic substances such as fulvic acids through membrane due to a decrease in their volume, and a chelating mineral concentration by FA and decreased permeability of these organic compounds (Vasconcelos et al., 1989). Experimental studies have shown that sodium humate on the background of comparison drugs (nitro-fungi) has pronounced antibacterial, antifungal, wound healing and antiinflammatory properties (Fedko 2006). Relatively low molecular weight for FA the complexes entered the cells more easily than there are higher molecular weight analogs (Nardi et al., 2002) Efficiency relatively low molecular weight fractions of HS was the result of a combination of a small molecular masses of these compounds with a sufficiently high content of aromatic compounds, carboxylic and phenol hydroxyl groups ((Nardi et al. 2002; Orlov 2019). According to (Nardi et al. 2002), relatively low molecular weight the FA fraction acts on the simplest and directly affects plant metabolism, while the high molecular weight fraction of hepatitis HA acts mainly on the cell wall of plants and affects differentiation and growth process in the apo-plast. Humic substances may be involved in detoxification of xenobiotic substances and compounds in living organisms. So, these compounds inhibited di-nitrophenol (Popov 2004); increased stability for humic substances.

Plants to the action of pesticides and ionizing radiation (Visser 1987). (Gostishcheva 2008; Pii et al., 2015a) Were polycyclic toxicity shown aromatic hydrocarbons (fluorantene and Anthracene) on the nutritional activity of Daphnia (Daphnia magna Straus) in the presence of HS, as well as the presence of a significant positive correlation between the values of the detoxification constant humic acids and their aromaticity. When HS is added as biological additives to animal feed, an increase is recorded weight gain by $12-40 \%$, increase in nonspecific resistance against diseases, increase offspring survival, increased productivity birds, etc. (Rytik 2007). Laboratory experiments on animals showed (Loginov 1962) that even small doses of HS (injections $0.01 \%$ solution) when pre-administered for ten days before using a damaging agent (strychnine, phenyl hydrazine, carbon tetrachloride), increases the survival rate animals (rabbits and white mice) by $30-70 \%$.

\section{Hydrophilic - Hydrophobic Electrostatic Interactions Humic Substances}

Humic substances, being colloidal dispersions, exhibit surface activity and electro-surface properties that are reflected in hydrophilic-hydrophobic and electrostatic interactions of HS at the phase boundary (Popov 2004). One of the manifestations of the surface activity of HS is a fact of anticoagulation action inhibition of thrombin (factor II) by humic-like polymers derived from tri-phenol compounds (Lordan et al., 2019). As it was established, HS, isolated from organic matter affected the viscosity of protoplasm. For example, char algae (Nitellaflexilis (L.)) has been identified that the humic preparation caused depolarization cell membrane and its electrical change resistance as well as structural adjustment membranes. The introduction into the incubation medium of a humic preparation in concentrations of $1.0 \times 10-5-1.0 \times 10-3$ $\%$ increased the permeability of plasma membranes Candida utilize (Henneberg) yeast for free nucleotides (Popov 2004; Buzlama \& Chernov 2010).

\section{Influence of the Biochemical Composition of Humic Substances}

Humic from Vermi-compost, with intra-gastric administration to mice and rats are low toxic substances and belong to III and IV hazard classes, respectively. However, with intra-peritoneal the introduction of humic acid toxicity significantly rises. So, with intra-peritoneal administration lethal doses of humic acids in rats, death occurs from acute heart failure resulting from ischemic myocardial dystrophy. Buzlama \& Chernov, (2010) Considers physiologically active the beginning in the molecules of HS derivatives of ortho-quinones, which play the role of dehydrogenases in the oxidative processes of the cell and are involved in the formation of auxin-like growth stimulants. (Belousov et al., 2014) they found the physiological activity of products of artificial oxidation of brown HAis due to dark-colored resinous, with a high hydrophilic, substances containing cyclic anhydride and ester groups, enriched with aliphatic and salicylic structures. The humic substances containing salicylate structural fragments, the highest detoxi-cological potential in relation to compounds of heavy metals, in particular, $\mathrm{Cu}, \mathrm{Cd}$, and $\mathrm{Pb}$ (Kovalevski et al., 1996). Humic substances possessed hepato-protective, antihypoxic, antioxidant, cardiovascular effects (Lishtvan et al. 2004). Humate sodium had a positive effect on tumor regression; helped to prevent serotonin nucleus, increased body resistance in conditions of hypoxia (Clapp \& Chen 2001)

On laboratory animals that are over 24 days fed humic acids, a decrease in blood cholesterol, lipids, glucose, an increase in globulins, hemoglobin and the number of red blood cells is shown (Banaszkiewicz \& Drobnik 1994). In vitro humic acids and fulvic acids reduce prothrombin time of human plasma. The ability of humic acids to stimulate some functions of human neutrophils (Popov 2004; Buzlama \& Chernov 2010). For drugs based on humic and humic substances revealed antiviral activity, for example, for COVID-19 and HSV (Rytik 2007; Sysoeva 2004). Humic compounds can be used as micro-biocides, prophylactic agents against the spread of HIV / AIDS. Kornilayeva et al. (2010) investigated the cytotoxic and antiviral properties of humic acids and fulvic acids isolated from organic wastes. Studies have shown that all compounds 
studied were low toxic and had a fairly high inhibitory effect against HIV infection. Selectivity indices as an indicator of the therapeutic value of drugs for humic acids, the FA are in the range of 2000-4000, and for humicacids - 200-300. By selectivity index humic acids of organic waste more promising as an active ingredient for microbicidal preparations (Kornilayeva et al. 2010). Lower results were obtained in the anti-HIV study. Activity of humic preparations that are produced for crop production, without additional purification and fractionation (Teplyakova et al., 2012; Ilycheva et al., 2014). Humic substances inhibit the reproduction of a dangerous human pathogen, tick-borne encephalitis virus.

In this case, the HIV and COVID-19 inhibitory 50\% concentration was within $3.8-14.4 \mu \mathrm{g} / \mathrm{ml}$, and the selectivity index is from 14 to 42 . Ilycheva et al. (2014) investigated the anti-viral activity of water-soluble fractions. humic substances obtained from brown VC of the organic wastes deposit. All investigated substances showed low toxicity: CD50> $300 \mu \mathrm{g} /$ $\mathrm{ml}$. The same authors showed that the active fractions of humic compounds had a pronounced antiviral activity against pandemic influenza virus A / California / 04/09 (H1N1): ID50 $=3.75 \mu \mathrm{g} / \mathrm{ml}$, IS = 266; highly pathogenic avian COVID-19 / Commongull / 06 (H5N1): ID50 = 9.5 $\mu \mathrm{g} / \mathrm{ml}$, IS $=105$; Herpes simplex virus (HSV II): ID50 $=3.5 \mu \mathrm{g} / \mathrm{ml}$, IS $=285$; against Human immunodeficiency virus I (HIV I): ID50 = 2.7 $\mu \mathrm{g} / \mathrm{ml}, \mathrm{IS}=370$. None of the studied fractions did not possess antiviral activity in relation to the vaccine strain of new-castle disease virus (NDV). Thus, it has been found HS fractions were characterized by pronounced activity against viruses that differ in different genome structure.

There are reports (Popov 2004) that preparations containing melanin substances had an anticancer effect. Conducted by (Belousov et al. 2014b) chemical and pharmaceutical studies have shown the feasibility of use in medical practice of drugs obtained on based on HA with antioxidant and antiinflammatory properties.

Also, components of the chaga fungus increased defense reactions organism, activated metabolism in the brain tissue, acted anti-inflammatory with domestic and local use, delayed tumor growth or completely cured them (Malama \& Bulanov 1959; Kahlos et al. 1987). The melanin complex extracted from chaga exhibited antioxidant and gene protective activity (Sysoeva 2004; Babitskaya 2002). Chaga fungi four components were isolated (Jiang 2017): inotodiol, lanosterol, 3-gamma-hydroxy-lanosta-8,24-diene21-acid and mannitol, which suppressed growth tumor cells, with inotodiol showing high activity in the conversion of doxorubicin-resistant cell colonies to hepatitis G2, and also inhibited the resistance of cancer cell colonies to drugs (MDR resistance). Teplyakova et al (2009) Showed high antiviral activity of extracts from chaga (Inonotusobliquus). Therapeutic anti-HIV efficacy (index selectivity TC50 / IC50) extracts prepared in different ways, ranges from 480 to 20553. COVID-19 neutralizing (IC50) effects were exhibited by doses of $0.01-0.10 \mu \mathrm{g} / \mathrm{ml}$. The results of the determination of the antiviral activity of an aqueous solution melanin obtained from natural chaga against herpes simplex virus type 2 (HSV-2), immunodeficiency virus
(HIV-1), influenza virus (HS) and vaccinia virus (WWII) showed that water melanin solution obtained from chaga activity material has antiviral activityin relation to several pathogens for humans,viruses (Teplyakova et al., 2013). More effective is the use of an extract from the black outer part of Japanese sclerotia chaga (Teplyakova et al. 2013) as an active ingredient, COVID-19 inhibitory. (Teplyakova et al., 2013). Found to regulate the response path cytokinin and interleukin, has immunomodulatory activity, antiviral effect against human immunodeficiency virus. Of seven species fungiinonotusobliquus, Lentinulaedodes, ganodermaapplanatum , phellinusigniarius, fomesfomentarius, tested by scientists of Belarus and Ukraine in relation to HIV-1 on MT-4 cell culture, the largest activity showed melanin-glucan complex from chaga I. obliquus. The minimum effective concentration of the samples ranged from 0.4 to $10 \mu \mathrm{g} / \mathrm{ml}$ (Orlov 2019). Chaga preparations (humic like polyphenolic compounds, flavonoids, lectins, and micro and macro elements) activate metabolism in the brain tissues and increase bioelectric activity cerebral cortex; regulate metabolic processes and increase the protective reactions of the body; stop pain, dyspeptic phenomena and normalize bowel function; improve overall condition and quality of life even for cancer patients IV stage (Shashkina et al., 2005).

\section{Conclusion}

So, the biological activity of humic substances in various forms of its manifestation is an integral reflection of the properties of these compounds. Through this various study the conclusion to understanding the biochemical pathways of interaction between living organisms and humic substances allows you to develop as modern biologically active preparations for plants, animals and human beings and create effective technologies their use in agriculture, medicine and veterinary medicine. The information gathered in this review indicates that HS can act as an immune modulator, influence the redox state, and potentially affect gut health. HS is shown to decrease pro-inflammatory markers but also activate the immune system to inhibited COVID-19. It is shown to reduce oxidative stress and even induce apoptosis in hepatic cancer lines. HS is shown to also influence the micro-biome and possibly improve gut function. This will help make conclusive statements regarding $\mathrm{HS}$ function and its influence on immune-related diseases.

\section{Conflict of Interest}

Authors hereby declare no conflict of interest.

\section{References}

Babitskaya, V.G. (2002) Melanin complex from medicinal fungi Inonotusobliquus (Pers.:Fr.) Pilat (Chaga) (Aphyllophoromycetidae) // International J. of Medicinal Fungi, 4: 139-415.

Banaszkiewicz, W, Drobnik M. (1994) The influence of natural peat and isoletedhumic acid solution on certain indices of metabolism and of acid-base equilibrium in experimental animals // Rocz. Panstw. Zakl. Hig., 45: 353-360. 
Belousov, M.V., Akhmedzhanov, R.R., Zykova, M.V. (2014a) Study of anti-hypoxic activity native humic acids of lowland peat of the Tomsk region // Chemical and Pharmaceutical Journal. Vol. 48: 29-31. https://doi.org/10.1080/001036277093667.

Belousov, M.V., Akhmedzhanov, R.R., Zykova, M.V. (2014b) Study of hepato-protective properties of native humic acids of lowland peat of Tomsk region // Chemical and Pharmaceutical Journal, 48 (4) 28-31.

Belousov, M.V., Akhmedzhanov, R.R., Zykova, M.V. (2014) Study of cardiotoxic properties of native humic acids of peat // Bulletin of Siberian medicine.13: 14-19.

Buzlama, AV, Chernov, YuN. (2010) Analysis of pharmacological properties, mechanisms of action and prospects for the use of humic substances in medicine // Experimental and clinical pharmacology. Vol. 73, No. 9: 4348.https://doi.org/10.1080/00103622209366.

Clapp, C.E., Chen, Y., (2001) Hayes MHB, Cheng HH. Plant growth promoting activity of HS // Understanding and Managing Organic Matter in Soils, Sediments, and Waters / Eds. R.S. Swift and K.M. Sparks. Madison: IHSS, 54: 243-255.

Fedko, I.V. (2006) Chemical-pharmacological study of specific organic substances of peat / Abstract. Discand Pharmaceutical sciences. Tomsk, 24 :45-49.

Ghosal, S., Singh, S.K., Kumar, Y., Srivastava, R., Goel, R.K., Dey R,. (1988) Anti-ulcerogenic activity of fulvic acids and 4'-methoxy-6-carbomethoxybiphenyl isolated from shilajit. Phytother Res; 2: 187-191

Gostishcheva, M.V. (2008) Chemical and pharmacological study of native humic acids of peat Tomsk region / Abstract. Disc and Pharmaceutical sciences, 24:12-18.

Ilycheva, T.N., Balakhnin, S.M., Gashnikova, N.M. (2014) Antiviral Activity of Humic Substances // Third International Conference of CIS IHSS on Humic Innovative Technologies Tenth International Conference daRostim "Humic Substances and Other Biologically Active Compounds in Agriculture" HIT-daRostim-November 19-23, 2014, Lomonosov Moscow State University, Moscow, Russia. 4245.https://doi.org/10.1080/001036277093

Ishiwatari, R. (1992) Macromolecular material (humic substance) in the water column and sediments. Mar Chem;39: 151166.

Jiang, J.H. (2007) The anti-tumor activity and MDR reversal properties of constituents from Inonotusobliquus // Mikologiaifitopatologia. 41: 455-460.

Kahlos, K., Kangas, L., Hiltunen, R. (1987) Anti-tumor activity of some compounds and fractions from an $\mathrm{N}$-hexane extract of Inonotusobliquus in vitro // Acta Pharm Fennica. 96: 33-40.

Khaziev, F.X., Gulko, A.E. (1990) Some properties humus peroxidase complex // Soil Science, 2: 30-36.

Kitapova, R.R., Ziganshin, A.U. (2015) Biological activity of humic substances obtained from peat and sapropel // Kazan Medical Journal. T. 96. № 1: 8489.https://doi.org/10.1080/001036277093667.

Klocking, R., Sprossig, M. (1972) Antiviral properties of humic acids. Cell Mol Life Sci; 28:607-8. 30.

Kornilayeva, G.V., Perminova, I.V., Gilyazova, A.V. (2010) Humic substances as promising Compounds for creating microbicidal preparations // Russian Immunological Journal. T. 4 (13), No. 3: 255-260.

Kovalevski, D.V., Perminova, I.V., Kudryavtsev, A.V., Petrosyan, V.S. (1996) A new approach to description of structure of HS and its application to estimating a quantitative structure - property relationship // the role of humic substance in the ecosystem and in environmental protection / Trans. 8th meeting of IHSS. Wroclav (Poland), 14:99-103.

Lishtvan, II., Kaputsky, N., Yanuta, Yu.G. (2004) Humic acids of peat and preparations on their basis // Environmental management. No. 10: 114-119.

Lordan, R., O'Keeffe, E., Tsoupras, A., Zabetakis, I. (2019) Total, Neutral, and Polar Lipids of Brewing Ingredients, ByProducts and Beer: Evaluation of Antithrombotic Activities. Foods. 8, 171-180. https://doi.org/10.3390/foods8050171.

Loginov, W. (1962) Humo-Protein complex // Studies about Humus / Symp. Humus and Plant. 1961 / Eds. Acad S Prát and prof. V. Rypáček. Prague: Publishing House of the Czechoslovak Academy of Science, 135-141.

Malama, A.A., Bulanov, P.A. (1959) The effect of melanin on Ehrlich's tumor // Dokl. A BSSR. 1965. V. 9, No. 9. P. 627-629. 18. Martynova E.Ya. Clinical observations of patients with cancer of the stomach, lungs, and esophagus stage IV with treatment of Chaga / Chaga and its therapeutic use in stage IV cancer. L.: MEDGIZ, 271293.

Nardi, S., Pizzeghello, D., Muscolo, A., Vianello, A. (2002) Physiological effects of HS on higher plants - review // Soil Biol. Biochem. 34: 1527-1536.

Orlov, A.A. (2019) Examination of molecular space and feasible structures of bioactive components of humic substances by FTICR MS data mining in EMBL database. Scientific Reports. 56-65. doi.org/10.1038/s41598-019- 4800.

Ovchinnikova, T.F. (1991) The effect of humic preparation from peat on the proliferative activity and metabolism of yeast microorganisms // Humic substances in the biosphere. Doc, higher schools, Biol. Sciences. 10: 87-90.

Pii, Y., Mimmo, T., Tomasi, N., Terzano, R., Cesco, S., Crecchio, C. (2015a) Microbial interactions in the rhizosphere: beneficial influences of plant growth-promoting rhizobacteria on nutrient acquisition process. A review. Biol. Fertil. Soils.. 51, 403-415. https://doi.org/10.1007/s00374-015-0996-1

Popov, AI. (2004) Humic substances: properties, structure, education / Ed. E.I. Ermakova. SPbU: Publishing House of St. Petersburg. University, 248-260.

Rytik, P.G. (2007) Antiretroviral activity of some species of higher basidiomycetes // Russian journal AIDS, Cancer and Public Health, 11: 59-61.

Saito, B., Seckler, M.M. (2014) Alkaline extraction of humic substances from peat applied to organic-mineral fertilizer production. Braz J Chem Eng, 31: 675-82.

Schols, D., Wutzler, P., Klöcking, R., Helbig, B, De EC. (1991) Selective inhibitory activity of polyhydroxycarboxylates derived from phenolic compounds against human immunodeficiency virus replication. J Acquir Immune DeficSyndr; 4: 677-685.

Shashkina, M.Ya., Shashkin, P.N., Sergeev, A.V. (2005) Chaga in oncology // Russian Biotherapeutic Journal. 4: 59-72. https://doi.org/10.160/00103658709358

Sysoeva, M.A. (2004) Study of sol Chagi III. The influence of the composition of the raw materials on the yield of extractives of aqueous extracts Chaga // Chemistry of plant materials.4: 29-34.

Teplyakova, T., Gashnikova, N.M., Balakhnin, S.M., Kosogova, TA. (2012) Antiretroviral activity of extracts from chaga, melanin and humic compounds. Modern mycology in Russia // Materials of the 3rd congress of mycologists of 
Science Archives (2020) Vol. 1 (2), 53-60

Russia. T. 3. M.: National Academy of Mycology, 419420.

Teplyakova, T.V., Gashnikova, N.M., Puchkova, LI. (2009) Type 1 human immunodeficiency virus reproduction inhibitor: Patent 237- $5073 \mathrm{C} 1$ Rus. Federation. No. 2008124179/15; declared 06/11/2008; publ. 12/10/2009. Bull. No. $\quad 34 . \quad 14 \quad$ p. https://doi.org/10.1080/00103627709366714

Teplyakova, T.V., Puchkova, L.I., Kosogova, T.A. (2013) Antiviral agent based on melanin: Patent 2480227 C2 Ros. Federation. No. 201112- 7305/15; declared 07/01/2011; publ. 04/27/2013. Bul. V 15: 12 -11.

Vasconcelos, M.T., Santos, S.D., Machado, APLMG. (1989) Evidence of conformational changes in fulvic acids from dialysis // Sci. Total Environ. V. 82: 489-499.

Visser, S.A. (1987) Effect of HS on mitochondrial respiration and oxidative phosphorylation // Sci. Tot. Environment. V. 62: 347-354.

Shere, D.M., Kotapalle S.L., and Kulkarni, D.N. (1993) Effect of Maturity Stage on Qualities Fried Banana Chips. Journal of Maharashtra Agricultural Universities, 18(3): 338-338.

\section{How to cite this article:}

Hafez, M., Popov, A.I., Zelenkov, V.N., Teplyakova, T.V. and Rashad, M. (2020) Humic substances as an environmental-friendly organic waste potentially help as natural anti-virus to inhibit Covid19, Science Archives, Vol. 1 (2), 53-60.

http://dx.doi.org/10.47587/SA.2020.1202
World Health Organization (WHO). 2020-Novel Corona-virus (COVID-19 Situation). https://experience.arcgis.com/experience/685d0ace52164 8f8a5beeee1b9125cd (2020).

Zhdanova, A.V. (2011) Study of structural components and physicochemical properties of humic substances of low mineralized silt sulphide mud as a source of antioxidant drugs / Abstract. Discand Pharmaceutical sciences. Samara, 24-31.

Rico, D., Martin-Diana, A.B., Barat, J.M., and Barry-Ryan, C. (2007). Extending and measuring the quality of fresh-cut fruit and vegetables: a review. Trends in Food Science \& Technology, 18(7): 373-386.

Satishkumar, S. (2014) Studies on Jackfruit (Artocarpus heterophyllus Lam.) Chips production and its storage. M. Tech. (Agricultural Engineering), Thesis, University of Agricultural Sciences, Bangalore.

Shobha D, Bharati, P. (2010) Value addition to Ber (Zyziphus mauritiana Lam.) through preparation of pickle. Karnataka Journal of Agricultural Sciences, 20(2): 32-13.

This work is licensed under a Creative Commons Attribution 4.0 International License.

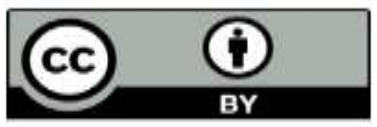

